\title{
DIREITO PENAL DOS VULNERÁ VEIS: UMA ANÁLISE CRÍTICA DA BUSCA DO RECONHECIMENTO POR MEIO DO DIREITO PENAL
}

\section{CRIMINAL LAW OF VULNERABLE: A CRITICAL ANALYSIS OF THE RECOGNITION SEARCH TRHOUGH CRIMINAL LAW}

\author{
${ }^{1}$ Daniela Carvalho Almeida Da Costa \\ ${ }^{2}$ Daniela Ramos Lima Barreto
}

\section{RESUMO}

Esse artigo parte da hipótese que o Direito Penal não é capaz de gerar reconhecimento. Tem por objetivo principal analisar, no quadro geral da expansão penal contemporânea, a aproximação entre o Direito Penal e a noção de vulnerabilidade como a porta de entrada para a reivindicação de uma produção penal especial para determinados segmentos. Identifica-se, nesse contexto, o que se denominará Direito Penal dos Vulneráveis, marcado por uma forte tendência ao recrudescimento, hipertrofia da função simbólica e pouca preocupação com reflexões acerca da racionalidade da sua produção ou com suas repercussões de ordem teleológica. Para tanto, adotar-se-á uma pesquisa de cunho bibliográfico, destacando as contribuições dos Direitos Humanos, da Vitimologia e da Criminologia. O artigo ainda ressalta o papel dos novos gestores da moral pública nesta mobilização e colhe, dos aportes da teoria do reconhecimento, subsídios para problematizar os reclamos dos movimentos sociais por criminalização.

Palavras-chave: Vulnerabilidade, Reconhecimento, Direito penal

\begin{abstract}
This article starts from the assumption that the criminal law is not able to generate recognition. Its main objective is to analyze, within the general framework of contemporary penal expansion, the closeness between the criminal law and the notion of vulnerability as the gateway or the justification to the claim of a special criminal production for certain segments. This article will identify in this context, what will be called criminal law of the vulnerable, marked by a strong trend towards recrudescence, hypertrophy of the symbolic function and little concern for reflections on the rationality of its production and its repercussions teleological order. To this end, it will adopt a bibliographic research, highlighting the contributions of human rights, victimology and criminology. The article also emphasizes the role of "new managers of public morals" in this mobilization and reaps, of the Recognition Theory contributions, subsidies to question the claims of social movements for criminalization
\end{abstract}

Keywords: Vulnerability, Recognition, Criminal law

\footnotetext{
${ }^{1}$ Doutora em Direito pela Universidade de São Paulo - USP, São Paulo - SP (Brasil). Professora da Universidade Federal de Sergipe - UFS, São Cristóvão - SE (Brasil).

E-mail: dancacosta@hotmail.com

2 Mestre em Direito pela Universidade Federal de Sergipe - UFS, São Cristóvão - SE (Brasil). Professora da Faculdade de Administração e Negócios de Sergipe, FANESE, Aracaju - SE (Brasil).

E-mail: danielar.limabarreto@yahoo.com.br
} 


\section{INTRODUÇÃO}

Nos dias atuais, encontra-se na centralidade do debate político, a questão do reconhecimento de certos segmentos sociais e a aceitação de que estes grupos ostentam maior suscetibilidade de violação de direitos, vivendo consequentemente, em situação de vulnerabilidade social. Também as demais questões que circundam essa problemática são trazidas à baila, tais como: a administração das tensões entre desigualdades e diferenças, o critério de justiça utilizado na condução dessa mesma gestão pelas sociedades contemporâneas, a eleição de políticas afirmativas para diminuição das desigualdades, entre outras implicações.

Observa-se que tal discussão não passa ao largo do Direito Penal. Dentre as diversas tendências em meio à expansão penal própria dos nossos tempos, uma, em especial, reflete no Direito Penal, a mobilização para satisfação dos reclamos da diferença.

Este trabalho tem como tema central o surgimento de um "Direito Penal dos vulneráveis", aqui entendido como a produção legislativa oriunda de grupos que procuram legislar no Direito Penal a afirmação das suas especificidades, a satisfação de suas necessidades de reconhecimento e a superação de sua condição de maior suscetibilidade à violação de seus direitos. Analisar tal fenômeno permitirá refletir sobre a própria função do Direito Penal e a legitimidade de seu discurso.

Justifica a presente pesquisa a exigência de uma reflexão crítica a respeito da produção legislativa, aqui chamada de "Direito Penal dos Vulneráveis", que emerge ante a necessidade indubitável de reconhecimento de direitos e promoção de igualdade, sob pena de, esquivando-se de tal análise, admitir-se a possibilidade de que todo esforço político e social de mobilização de tais segmentos, propiciados por seus anseios de reconhecimento de direitos e afirmação social, sejam convertidos em uma legislação penal inócua que redunde em uma transferência para o plano simbólico daquilo que deveria resultar em uma efetiva proteção.

Apresenta-se como desafio, tomado aqui como objetivo primordial, a necessidade de uma análise do fenômeno "Direito Penal dos Vulneráveis" que propicie o exame das fontes de onde este provem, das ideias que o sustentam e o desvelamento do tipo de mobilização social que lhe serve de pano de fundo. Tudo isso, com vistas, evidentemente, à consolidação de uma olhar crítico capaz de nos permitir situá-lo adequadamente no multifacetado quadro da expansão penal contemporânea. 
Nesse sentido, se empreenderá a busca, lançando mão da pesquisa bibliográfica de abalizadas fontes da Criminologia, da literatura de Direitos Humanos, da Vitimologia e da Filosofia Política. No curso metodológico escolhido, serão investigadas as significações da expressão vulnerabilidade, suas acepções, o itinerário percorrido na formação do conceito e a sua repercussão para o Direito Penal. Em seguida, buscar-se-ão nos aportes da teoria do reconhecimento, subsídios teóricos para a compreensão das demandas dos grupos vulneráveis por reconhecimento político e de direitos. Para, ao final, buscar entender a demanda desses segmentos por Direito Penal, verificando se esta coincide com a luta por reconhecimento.

A pesquisa proposta parte das seguintes questões norteadoras: seria o Direito Penal locus para reivindicações de reconhecimento? Poderá o Direito Penal prestar-se a ser instrumento para promoção de igualdade? O que querem os vulneráveis e o que pode o Direito Penal?

Trata-se de buscar enxergar a dimensão dos reclamos e das reivindicações dos chamados grupos vulneráveis, as quais são ao mesmo tempo, expressões de uma luta por reconhecimento de especificidades e identidades e de uma luta por igualdade de direitos, e, também, buscar mensurar o espaço e a importância que se tem atribuído ao Direito Penal nesse contexto. Como questões de fundo, tem-se sempre presentes a indagação acerca do que é justo na tarefa de tratar cada indivíduo de forma equânime e a dúvida acerca de qual a função do Direito Penal, quando se vislumbra nele, em última instância, um instrumento para promover a inclusão, onde há a exclusão e um recurso para promover direitos, onde há violação.

\section{O "DIREITO PENAL DOS VULNERÁVEIS": UMA VERTENTE ESPECÍFICA DA EXPANSÃO PENAL}

Observando aspectos da política criminal das sociedades contemporâneas, JesúsMaria Silva Sanchez identifica que nos círculos intelectuais jamais se ouviram tantas menções à necessidade de se reconduzir a intervenção punitiva estatal a um Direito Penal mínimo. Em que pese não existir um consenso a respeito do que exatamente vem a ser esse Direito Penal mínimo, ele é normalmente descrito como algo próximo do modelo de Direito Penal liberal o qual tem por objeto da repreensão estatal as condutas atentatórias à vida, à liberdade e à propriedade, com manutenção de máximas garantias ao indivíduo. Nesse sentido, os 
defensores do Direito Penal mínimo costumam descrever o alargamento dos domínios do Direito Penal como "uma cruzada contra o mal, desprovida de uma mínima fundamental racional" (SILVA SANCHEZ, 2000, p.21).

Paradoxalmente, ao mesmo tempo em que se enfatiza a urgência de um "enxugamento" do Direito Penal, ou seja, a necessidade de se restringir ao máximo as hipóteses autorizadoras da intervenção penal estatal, Silva Sanchez observa uma tendência claramente dominante na grande maioria dos países, consistente no clamor para a introdução de novos tipos penais e agravamento da pena dos já existentes.

Dentre os variados fatores que compõem o quadro geral da chamada expansão penal, interessa notar certa virada da Criminologia crítica, que defendia uma associação entre criminalidade e proletariado e, enfatizava o Direito Penal como forma de exclusão e crueldade e que, agora, passa a enxergar no Direito Penal uma forma de afirmação de direitos, defendendo a sua ampliação na medida em que importe um incremento de proteção de interesses de um dado grupo. Aqueles que até então eram destinatários do Direito Penal na forma de objeto de suas criminalizações, ou melhor, aqueles que eram vítimas da seletividade discriminatória do Direito Penal, passam a cada vez mais a se enxergar como vítimas em potencial e não como autores em potencial (SILVA-SANCHEZ, 2000).

É neste quadro que ganha relevância a referência à existência de atypische moralunternehmer (SCHEERER, 1985) ou os novos gestores atípicos da moral pública, que deixam de ser exclusivamente os tradicionais estamentos burgueses, para serem também representados pelos grupos feministas, ativistas, ecologistas, consumidores, entre outros; todos estes encabeçando uma tendência de ampliação do Direito Penal como forma de defesa de interesses de grupos. Subjacente a tudo isto, está a ideia, mais recentemente defendida pela Criminologia crítica, de que o delito praticado contra determinadas vítimas constitui violação de Direitos Humanos (SWAANNINGEN;TAYLOR, 1993).

Surpreende a contribuição da Criminologia crítica a esta vertente expansionista penal, pois ela, outrora defensora do abolicionismo, vem sendo decisiva na elaboração de novos processos de criminalização, como registrou Van Swaanningen ao observar que os criminólogos se tornaram sensíveis a novos temas, e passaram, no final da década de 80 do século passado, a deslocar seu interesse de estudo, que, então, passou das pesquisas sobre violência sexual e violência familiar, ou ainda sobre crimes econômicos e contra o meio ambiente, para concentrar-se nas violações de direitos humanos ou "outros crime cometidos pelo estado" (SWAANNINGEN, 2003). 
Novos processos de criminalização, dão origem a um "Direito Penal dos vulneráveis", assim entendido, como a produção legal, fruto da mobilização de segmentos que buscam legislar no Direito Penal, a afirmação de suas especificidades e a satisfação da necessidade de reconhecimento de suas identidades e de suas demandas de proteção.

Fundamentam-se tais processos no conceito de que violações de direitos humanos são crimes merecedores de severa repressão, e, na constatação de que determinados grupos sociais sofrem discriminação e têm negado o seu acesso às esferas de decisão política, quer seja em razão de critérios racistas, quer seja em razão de critérios sexistas, ou ainda uma combinação de variados e complexos mecanismos de exclusão, o que os faz vivenciar cotidianamente uma situação de subalternização e precariedade de garantias, a qual frequentemente ameaça a sua dignidade pelo sacrifício de seus direitos mais básicos

Esta tendência se faz presente no cenário das sociedades ocidentais pós-industriais contemporâneas. No Brasil tem relevante expressão, são exemplos de legislações penais criadas para proteger direitos de um grupo específico.: a lei 7716/89 que criminaliza as condutas de discriminação fundadas na raça, ou na cor; a lei 10.741/2003 que criminaliza condutas perpetradas contra a pessoa idosa, e a mais emblemática delas, a lei 11.340/2006, a chamada Lei Maria da Penha, que define a violência doméstica de gênero e estabelece um tratamento processual penal diferenciado para os delitos cometidos neste contexto.

Portanto, a esperança de encontrar no Direito Penal um freio ao desrespeito e à violação de direitos de determinados grupos, está presente no cenário social brasileiro, tanto quanto, desde a década de 1980 tem ganhado corpo em vários outros países, uma corrida por legislações penais próprias de um segmento, no influxo dos reclamos por igualdade e por reconhecimento.

\section{O CONCEITO DE VULNERABILIDADE E SUA REPERCUSSÃO PENAL}

\subsection{Vulnerabilidade e Direitos Humanos: A Existência de Grupos Vulneráveis como uma Constatação no Processo de Consolidação e Afirmação dos Direitos Humanos}

Tanto a noção de vulnerabilidade, que se plasmou ao longo do percurso em que se reconheceram os direitos do homem, como os seus reflexos no Direito Penal, estão 
relacionados com esforços para garantir a fruição desses mesmos direitos por todos, e conferir efetividade às conquistas emancipatórias.

O momento pós-guerra foi extremamente importante na consolidação e universalização dos Direitos Humanos. A declaração de 1948, proclamada pela Assembleia Geral das Nações Unidas, chamou-se Declaração Universal dos Direitos do Homem, e, deixou clara a pretensão de que os direitos ali enunciados fossem reconhecidos como valores universais em todo o globo terrestre. Em seu primeiro artigo, a Declaração Universal anuncia que "todas as pessoas nascem livres e iguais".

Ultrapassado o primeiro momento de afirmação da igualdade e de reafirmação dos direitos já conhecidos do mundo, por terem sido conquistas das revoluções burguesas, estes mesmos direitos passam a ser estendidos a uma série de sujeitos, que, por ocasião das lutas da burguesia, não eram enxergados como tais. É assim pois, que a Declaração Universal reconhece os direitos das mulheres, proíbe a escravidão, defende o direito dos estrangeiros, além de acrescer novos direitos, de natureza econômica ou social e de natureza cultural. Estes então novos direitos constituem-se em herança das lutas populares e das revoluções socialistas do século XX, como também das experiências sociais democráticas e laboristas europeias e do cristianismo social (TOSI, 2002).

Esse processo de ampliação acaba por se materializar, não somente como um alargamento da quantidade de direitos, mas também, como um acréscimo em qualidade de direitos. Nesse curso de desenvolvimento, os Direitos Humanos se universalizaram, se multiplicaram e se diversificaram. Quanto a esta última modalidade de ampliação, se quer, com isto, significar que foram melhores definidos os titulares de direitos e as pessoas passaram a ser consideradas não de maneira genérica e abstrata, mas em suas especificidades e nas suas diferentes possibilidades ser (TOSI, 2002). É desse modo, que ganham visibilidade os direitos das mulheres, das crianças, dos idosos, das pessoas com deficiência e das chamadas minorias étnicas.

Uma série de conferências temáticas passou a explicitar a preocupação de levar em conta as especificidades, para alcançar a efetividade dos Direitos Humanos e a pretensão de igualdade de direitos, de oportunidades e de dignidade que cabe a cada indivíduo. Também resultou dessa mobilização, um grande número de Convenções, Protocolos e outros documentos internacionais voltados à proteção e promoção de direitos de grupos específicos. 
Estabelece-se nas décadas seguintes à proclamação da Declaração Universal dos Direitos do Homem, um movimento no sentido de nomear, identificar e distinguir os variados sujeitos titulares dos Direitos Humanos, tendência cada vez mais forte a partir da década de 1970, atingindo grande relevância na década de 1990, quando o direito à diversidade é mais uma vez expresso na importante Declaração dos Direitos das Pessoas pertencentes a minorias Étnicas, Religiosas e Linguísticas de 1992.

A noção primária de vulnerabilidade está relacionada à maior suscetibilidade de violação de direitos, isto porque, constatou-se que a simples proclamação de direitos iguais a todos os homens não fora suficiente para modificação da realidade de subalternização e injustiça, a que algumas pessoas são expostas simplesmente por pertencerem a um dado grupo social ou por possuírem especificidades que os distinguem de uma maioria dominante.

Paradoxalmente, no momento em que se logrou o reconhecimento de direitos do homem em toda a sua especificidade e diversidade, também se verificou que esta mesma diversidade e especificidade frequentemente é utilizada como fator justificador de desigualdades e injustiças. Na busca por diminuir a distância entre os direitos enunciados e a realidade imposta aos segmentos vulnerabilizados, passou-se a examinar a vulnerabilidade no contexto das interações sociais que são por ela determinadas, isto é, de que maneira a condição de uma especificidade física, étnica ou cultural pode determinar que a vida de um indivíduo seja mais próxima ou mais distante daquilo que denominamos vida digna.

Foi com esse foco que se detectou que a vulnerabilidade encontra-se associada à noção de exclusão social, observada como fenômeno social multidimensional. Neste sentido, encerra uma concepção a qual vai muito além da ideia de pobreza, em que o que está em jogo é o acesso a bens materiais, tratando-se de algo que se dá na esfera exclusiva do econômico. Ademais, a noção de vulnerabilidade traz o fenômeno da exclusão observado de uma visada muito mais ampla, capaz de capturar em suas lentes, não somente a questão da falta de acesso aos bens necessários a uma vida digna, mas também outros processos exclusivos, como a desqualificação social, a desagregação identitária (GIDDENS, 2002), o prejuízo à intersubjetividade pelo desrespeito (HONNETH, 2003) e a anulação de alteridades.

A vulnerabilidade radica no mesmo substrato de onde afloram as dicotomias igualdade/desigualdades, igualdade/diferença e justiça/injustiça, revelando no caso dos segmentos vulnerabilizados, uma injustiça que não é somente material, mas simbólica (XIBERRAS, 1993), na medida em que, os valores a eles relacionados não são reconhecidos e se encontram banidos do universo simbólico predominante, o que traz como resultados 
práticos a invisibilidade social, o desrespeito e a pouca consideração social destinada ao grupo.

Nasce do discurso de Direitos Humanos a denúncia da existência da vulnerabilidade, como situação que aflige segmentos sociais, determinando-lhe precariedade material, fragilidade, ausência ou violação de direitos e pouca estima social, ao mesmo tempo em que, chama a atenção das Ciências Sociais que a observam como uma manifestação de interações sociais exclusivas, com profundas consequências para a dinâmica social em que estão inseridos os atores a elas submetidos, implicando assim, não somente na negativa de acesso a bens, mas também em prejuízos à autoestima de indivíduos e grupos, mediante processos intersubjetivos.

Deste modo, a vulnerabilidade passa a ser vista como o resultado negativo da relação entre recursos materiais ou simbólicos dos atores e o acesso às oportunidades sociais, o que se traduz em desvantagens para o seu desempenho ou mobilidade social (ABRAMOVAY, 2002).

Afastar as causas da vulnerabilidade social e minimizar-lhe as consequências, passa a ser uma das metas dos organismos internacionais de defesa de Direitos Humanos, sobretudo a partir da década de 1990, quando, de certa maneira, torna-se consenso a caracterização da vulnerabilidade como uma situação de potencial e inequívoca violação de Direitos Humanos, e delineiam-se duas tendências de enfrentamento da questão a partir da perspectiva do Direito Internacional dos Direitos Humanos: uma promocional, que tem como objetivo, fomentar, fortalecer e fazer avançar a igualdade e uma repressivo punitiva que, por sua vez, tem como meta, punir e proibir todas as formas de discriminação e demais violações de direitos nelas fundadas (PIOVESAN, 2005).

É justamente a leitura que alimenta a vertente repressivo punitiva do discurso de Direitos Humanos que enseja a aproximação da noção de vulnerabilidade social com o crime, isto é, os vulneráveis sociais passam a ser vistos como vítimas em potencial, de formas específicas de violência, determinadas pela sua própria condição de vulnerabilidade.

Essa forma de pensar é ao mesmo tempo capturada por algumas manifestações da mais recente Criminologia crítica, as quais passam a identificar a violação de Direitos Humanos com o crime. Do encontro do discurso de Direitos Humanos com o ponto de vista largamente absorvido por uma significativa parcela da Criminologia crítica contemporânea, efetuado no locus semântico da categoria vulnerabilidade, é que nasce o substrato ético a justificar, o aqui chamado, "Direito Penal dos vulneráveis". 


\subsection{Vulnerabilidade e Vitimologia: o olhar voltado às vítimas agregando significados e promovendo aproximação com o Direito Penal}

É imperioso lembrar a importância da Vitimologia no percurso de construção da ideia de vulnerabilidade, sua aproximação com os Direitos Humanos e a relevância dessa contribuição para a compreensão das repercussões do conceito de vulnerabilidade e seus reclamos na produção legislativa penal contemporânea.

A Vitimologia, ciência surgida em meados do século passado com os trabalhos de Benjamin Mandelson "The origins of Doctrine of Victimology” de 1947 e de Hans Von Hentig, "The criminal and his victmim" de 1948, inicialmente foi associada ao estudo da vítima do crime e vista como parte da Criminologia.

Há ainda quem questione a sua autonomia como ciência, todavia, hodiernamente é entendida de forma transdisciplinar, não se restringido em seu estudo às vítimas de crimes, mas, a todas as pessoas que tenham os seus direitos violados. Possui um amplíssimo horizonte de estudo que a aproxima dos Direitos Humanos e de tantas outras disciplinas.

Em sua perspectiva mais atual, a Vitimologia caminha lado a lado com os Direitos Humanos, seguindo na mesma direção, qual seja, aquela que persegue "o resgate da dignidade dos princípios fundamentais da pessoa humana, a lapidar defesa de pessoas e comunidades, aquelas que convivem com a marginalização e exclusão de seus direitos fundamentais" (PIEDADE JUNIOR, 2000. p.01).

O conceito primitivo de vítima remete-nos ao holocausto da religião judaica em que um animal é sacrificado ao "Deus de Abraão" como forma de demonstrar gratidão ou pedir a expiação de pecados (KOSOVSKY, 1990). Curiosamente, outro holocausto, desta feita o holocausto de milhares de judeus, colocado em curso pelo Estado Alemão Nazista, liderado por Hitler, está intimamente ligado aos fatos que ensejaram as reflexões propiciadoras do nascimento da Vitimologia enquanto campo específico de estudo. A observação que algumas pessoas nada fizeram para propiciar uma história de segregação e sofrimento, ocorrida naquele momento histórico, contribuiu para o início dos trabalhos da nova ciência (KOSOVSKI; SEGUIN, 2002), que resultaram na explicitação e elucidação da noção de vulnerabilidade, tal como aparece inicialmente, ligada aos fenômenos da negação, não efetivação e de violação de direitos, realidades muito mais amplas que o crime.

Muito embora os trabalhos iniciais de Vitimologia enfatizassem o estudo da vítima como a outra parte da chamada "dupla criminal" e ligassem o novo campo de estudo às 
investigações relacionadas à "precipitação do delito" pela própria vítima, o que foi seriamente rechaçado pelo movimento feminista (OLIVEIRA, 1999), hoje já se tem muito bem aclarado qual o seu campo de trabalho, o que foi feito tomando-se por base os resultados de um acalorado debate acerca de qual seria, de fato, a sua missão.

$\mathrm{Na}$ busca de definir qual seria a sua tarefa, os vitimólogos precisaram, antes de tudo, determinar quem ou qual seria a vítima, objeto de sua investigação. Dividiam-se entre aqueles que entendiam que vítimas, para efeito do estudo vitimológico, seriam apenas os sujeitos passivos de crime e os que acreditavam serem vítimas, objeto do estudo da Vitimologia, todos aqueles que de alguma forma experimentassem sofrimento, incluídas as vítimas do crime, das catástrofes naturais, das doenças e de toda sorte de desventura. À primeira perspectiva, chamou-se criminológica, à segunda, universal.

Kirchhoff (1990) conclui, com base nas reflexões de Separovic, Neuman e Elias, que a vítima, que interessa à Vitimologia, é toda vítima de um sofrimento causado pelo homem, desde que este se constitua em uma violação de Direitos Humanos. Tal enfoque coloca como equivalentes, violação de Direitos Humanos e crime e, acaba assim, por estabelecer uma aproximação entre Vitimologia e Direitos Humanos e uma coincidência entre as noções de grupos vulneráveis e vítimas.

A noção de vulnerabilidade exsurge pujante na Vitimologia. Pode-se reconhecê-la inscrita em classificações de vítimas como "vitimas vulneráveis", "vítimas coletivas", "vítimas da sociedade" (KOSOVSKI,1990), dentre outras, e encontra-se presente como questão pressuposta à própria definição do objeto da nova ciência, o porquê determinadas pessoas ou grupos parecerem ostentar uma condição de vítimas em potencial.

Destarte, Vitimologia e Direitos Humanos se encontram no significado da expressão vulnerabilidade. Ela contribuiu, não somente para cristalização de uma noção de vulnerabilidade, expressada na verdade, em uma ampliação das significações atribuídas à vítima, mas também, contribuiu para o surgimento da vertente expansionista penal aqui estudada, na medida em que, as mobilizações decorrentes da repercussão de se trazer ao debate público a necessidade de atenção às vítimas, fizeram nascer em diversos países um movimento bastante coeso voltado a sua assistência, que associado a outros movimentos sociais, como o movimento feminista, movimento de defesa de direitos de crianças e adolescentes, dentre vários outros, tem defendido a elaboração das legislações penais específicas para determinados segmentos. 


\subsection{Vulnerabilidade e Criminologia: os pressupostos da Criminologia Social, a Criminologia Crítica e sua mudança de direção}

Embora não se mencione a palavra "vulnerabilidade" nos escritos da chamada Criminologia Social ou Sociologia Criminal, como se costuma nominar aquelas variadas concepções, desenvolvidas desde a década de 30 do século passado, que superaram o paradigma etiológico no estudo da criminalidade, transmudando-o para um paradigma social, é possível observar que a noção de vulnerabilidade, muito embora no momento em que foram elaborados os estudos a que nos referimos, jamais tivesse sido enunciada nos contornos em que hoje a conhecemos, encontrava-se pressuposta, implícita e, como vetor de explicações, voltada em sentido contrário ao hodiernamente utilizado para expressão "grupos vulneráveis".

É que a vulnerabilidade implícita nos estudos da Criminologia Social, e nas teorias da reação social, determinava quem seriam aqueles que adentrariam à categoria dos desviados, daqueles que seriam objeto da seletividade do Direito Penal. Na perspectiva do "Direito Penal dos vulneráveis", ela determina quem é que por sua especificidade e pela condição que dela advém, será vítima em potencial de específicas formas de violação, consideradas de peculiar gravidade, em razão de serem violações de Direitos Humanos.

Revisitando as formulações da chamada Criminologia Social, é possível detectar que já estes estudos parecem "apontar pistas" acerca da dimensão da vulnerabilidade, ao definir o destinatário do Direito Penal como o individuo estigmatizado, pertencente a estratos sociais com menos chances e oportunidades de alcançar os fins definidos culturalmente como sucesso, e, pertencentes a grupos politicamente não dominantes.

Tais definições são fruto da produção da Criminologia a partir da década de 1930, especificamente das teorias das subculturas, as quais indicam que a criminalidade é definida pelas dificuldades que certos indivíduos enfrentam, em razão da estratificação social, de acessarem os meios legítimos para alcançar os fins culturalmente tidos como desejáveis; das teorias do labelling approach ou reação social, que, tomando como base seu ponto de observação, qual seja, do esforço de enfrentamento do problema da definição do delito, constata que essa definição de criminalização passa por mecanismos de estigmatização de determinados sujeitos e, das teorias conflituais as quais enunciam que a definição de criminalização advém das relações de hegemonia entre classes ou grupos; hegemonia essa, que se materializa no poder de definição de um grupo e na submissão à criminalização por outro (BARATTA, 2002). 
Isto posto, vê-se que embora ainda não houvesse uma formulação da ideia de vulnerabilidade como hoje se apresenta, as características que a definem, já haviam sido em certa medida, apreendidas pelas observações da Sociologia Criminal e, em diversas de suas teorizações, foi identificada exatamente como razão a determinar que sujeitos fossem objeto da seleção do sistema penal.

Para BARATTA (2002), é justamente com base na teoria do labelling approach e nas teorias do conflito que se efetua na Sociologia Criminal contemporânea, a passagem de uma Criminologia Social liberal para uma Criminologia crítica. Esta por sua vez, de matriz marxista em suas principais manifestações, buscou elaborar uma teoria materialista do desvio a guiar uma política criminal alternativa, orientada pelos interesses das classes subalternas.

Em suas formulações, a Criminologia Crítica identifica que o Direito Penal é por natureza um direito desigual e aqueles que são alcançados pelo seu controle, são recrutados das classes subalternizadas. Permanece a identificação daqueles que ostentam a condição de vulnerabilidade social (pouco acesso aos bens materiais e não reconhecimento simbólico) com os destinatários da criminalização.

É mesmo na vertente da Criminologia Crítica, no entanto, que acontece uma virada conceitual acerca da vulnerabilidade: algumas de suas manifestações passam a identificar violações de Direitos Humanos como crimes e, ao lado disso, defender novos processos de criminalização, em que aqueles segmentos, antes colocados como destinatários do movimento criminalizador, passam a ser enxergados como vítimas em potencial. É assim que, por meio da Criminologia, pode-se vislumbrar como os vulneráveis, aqueles excluídos não só materialmente, mas também politicamente, outrora vistos exclusivamente como potenciais destinatários da persecução penal, passam a buscar no Direito Penal uma proteção de seus interesses, e, vislumbra-se ainda, como, desde à "reviravolta" da Criminologia crítica, uma relevante parcela do pensamento progressista passa a defender os Direitos Humanos, servindo-se das estruturas de poder e de controle antes apontadas como fontes de violações. Saí de cena a negativa às estruturas de poder, abrindo espaço para a vontade de servir-se delas mesmas. 


\section{SCHEERER E OS GESTORES ATÍPICOS DA MORAL PÚBLICA: PODE O DIREITO PENAL IMPOR UMA MORAL?}

SCHEERER (1985) é importante referência no estudo que aqui se empreende. O autor identifica que os "gestores da moral pública", outrora recrutados dos seguimentos conservadores, agora são chamados entre os "novos movimentos sociais" que se diversificam em uma multidão variada de correntes contraculturais, formadas a partir da década de 70 do século $\mathrm{XX}$, em quase todos os países industriais capitalistas, daí por que os chama de "atípicos".

Para o autor, a partir de 1970, modificam-se os temas de reivindicação social, antes, mais próximos de utopias políticas abstratas como "comunismo" ou "internacionalismo", temas vistos com alguma desconfiança por alguns, os novos temas passam a ser colhidos na realidade do cotidiano vivido por cada um dos sujeitos.

Explica esse fato, a observação que relevantes modificações sociais, tais como a emergência de novas identidades, o reconhecimento de novos direitos, a ampliação do contingente de pessoas politicamente capazes de serem considerados sujeitos de direitos, a destruição do meio ambiente e a necessidade de controle da degradação/exploração do planeta para a continuidade da vida, acabaram por gerar um grande número de processos e de novas formas de interação que tiveram como resultado difundir uma nova moral ou ao menos “conteúdos novos de uma velha moral” (SCHEERER, 1985, p.272, tradução nossa).

Nesse contexto, enfatiza-se que da análise dos "novos movimentos sociais" e de sua repercussão na atividade parlamentar, conclui-se que esta aflui para o campo político da legislação penal levando-a recepcionar um número elevado de conflitos temáticos, o que atesta certa "reviravolta" em relação às antigas correntes de reivindicação.

$\mathrm{O}$ autor registra que o comportamento dos movimentos sociais se modificou rapidamente nos últimas décadas. Se numa primeira fase, em 1960, eles se denominavam "libertários", "anti-institucionais" e "anti- estatais"; numa segunda fase, no início dos anos de 1970, eles adotam uma posição de diálogo, atuando como interlocutores junto às instituições em

1 Segundo SCHEERER (1985), essa categoria, muito conhecida na literatura sociológica, expressa a condição do ator social que ocupa lugar central nos "movimentos orientados em direção as normas e a valores". Também referidos como "empreendedores morais". Caracterizam-se na análise de Scheerer, por atuar com falta de conhecimento das questões sociais que abordam, por sua incapacidade de analisar os processos sociais em que estão inseridos, por sua atuação ingênua, pautada em uma ética absoluta e apaixonada, ao mesmo tempo em que, relativizam os meios necessários para atingir os fins políticos de seu interesse. O autor utiliza como ilustração os religiosos das pequenas cidades americanas do início do século passado, que buscaram por meio da lei rechaçar os costumes diversos trazidos à realidade social pelos imigrantes irlandeses, perseguindo assim, obrigar a todos que se sujeitassem às suas concepções de moral servindo-se para isso, da lei penal como meio de coerção.

Neste sentido ainda BECKER (1973). 
relação a um amplo desacordo a respeito de valores, de justiça e de normas. Afloram aí as reivindicações de reconhecimento, muito embora tenham ficado em primeiro plano, as reivindicações de igualdade diante da lei ante as reivindicações do direito fundamental pela diferença; já na terceira fase, iniciada no fim dos anos 70 e início dos anos 80 do século passado, ocorre uma redução da perspectiva dos movimentos sociais de sua participação nas instituições e nas discussões políticas travadas com o Estado. Adota-se uma posição de barganha simplificadora e redutora das grandes questões presentes nas complexas sociedades: "Eles não querem fazer mais nada para o Estado se este não promete fazer algo por eles" (SCHEERER, p.274, tradução nossa).

Conduziu a esta terceira fase, o resgate da importância conferida ao Direito Penale a ampliação das expectativas simbólicas nele depositadas ocorridos no final dos anos 70 do século XX, quando se abandona a posição de considerá-lo algo ruim, e reabilita-se a ideia de uma "justiça", a qual se possa chegar por meio de modificações positivas de direito, fundadas no princípio da culpa e da imputação, conferindo ao Direito Penal o papel de organizador universal e simbólico da hierarquia dos valores e dos bens.

No olhar de Scheerer, os movimentos sociais revelam-se nesse percurso, protagonistas de uma força de criminalização que põe fim a uma fase de descriminalização, e invertem concepções que prevaleciam anteriormente, favoráveis à retirada do Direito Penal do domínio dos delitos em matéria de comunicação e de moral. Ademais, o ímpeto criminalizador dos movimentos sociais parece fazer pouco caso da finalidade instrumental do Direito Penal ou de qualquer exigência de coerência e enfatiza-se a importância da representação simbólica daquilo que é justo e verdadeiro, na perspectiva dos interesses de cada um dos grupos atuantes, enquanto novos empreendedores morais².

Na percepção de Scheerer (1985), o esforço não é de construir uma ordem jurídica que seja justa e atenda aos anseios de proteção, eleitos como relevantes em uma dada sociedade, trata-se de querer ver no Direito Penal seus valores, sua forma de vida, suas características específicas, inscritas positivamente no quadro simbólico, pela ameaça da pena e do castigo. Tal uso do Direito Penal apresenta-se bastante problemático, uma vez que, entre as suas tarefas, seguramente, a afirmação de valores morais não encontra lugar.

2 A este respeito Scheerer vaticina: "Aos olhos dos novos movimentos sociais, o Direito Penalencontra assim a dignidade quase metafísica que perdera. Ele se torna o meio de fixar por escrito e de modo simbólico o novo sistema de valor. Que a lei seja, na sua acepção técnica, 'eficiente' ou, sobretudo, 'contraprodutiva', não parece ser mais importante aos novos especialistas em delitos: o importante é ter a sua lei” (SCHEERER, 1985, p. 274). tradução livre. 
Evidentemente, novas formas de pensar e interpretar o mundo, ou novas formas de eleição e hierarquização de valores, surgiram, propiciadas pelo confronto do homem, com mudanças muito significativas tais como: a progressiva ampliação dos direitos do homem, alcançada tanto na esfera internacional de Direitos Humanos, como em nível interno, nos estados constitucionais; a admissão nestas ordens, de novos bens de titularidade coletiva como o meio ambiente saudável e equilibrado e a segurança das relações econômicas e de consumo; a emergência de uma aproximação muito maior entre culturas diversas, ocasionada pela diminuição das distâncias geográficas, ante os variados aspectos da globalização e o acirramento das tensões ocasionadas pela dificuldade apresentada pelas modernas sociedades de conviver com a diversidade, entre outros processos relevantes. A difusão dessas novas formas de pensar e de agir com pretensão de representar um padrão normativo, exprime o que Scheerer (1985, p.271) chamou de novos aspectos de uma velha moral.

Defende-se que uma crítica ao Estado e ao Direito deve passar por uma fundamentação ética de suas ações e a efetivação de uma "justiça" passar pela supressão do afastamento, que se deu em consequência do positivismo jurídico, das questões do Direito e do Estado e a perspectiva axiológica (HÖFFE, 2001). No entanto, a questão sempre problemática é a de definir que valores, interesses e direitos poderiam ostentar um caráter absoluto o qual autorizasse a sua imposição a todos.

A própria ideia de que a todos os homens é devido um núcleo de direitos inalienáveis, independentemente de quaisquer outras considerações, em que se funda a doutrina de Direitos Humanos, aspira constituir-se em uma nova moral, embora até hoje sejam empreendidos esforços no sentido de dotar-lhe de uma fundamentação, o que demonstra ser de fato, uma questão difícil, contemplar as diferenças e necessidades específicas e, ao mesmo tempo, estabelecer um núcleo de valores universais a guiar uma referência de justiça.

Ademais, a experiência histórica parece apontar como algo nada promissor a utilização do Direito Penal, como instrumento para fixação e imposição de valores, fato sempre associado a políticas criminais de caráter autoritário. 


\section{RECONHECIMENTO: AS CONTRIBUIÇÕES DE CHARLES TAYLOR, AXEL HONNETH E NANCY FRASER}

O conceito de reconhecimento encontra-se na ordem do dia das discussões políticas, e a expressão ganha relevância no discurso de sociólogos, cientistas políticos, filósofos e juristas, pois acaba por refletir um grande desafio dos nossos tempos: como eleger critérios de justiça capazes de conferir vida digna a todos, em meio aos reclamos da diferença, que a todo tempo afloram da complexidade das sociedades contemporâneas.

É exatamente neste contexto, da mediação da tensão entre igualdades e diferenças nas hodiernas sociedades, que o "Direito Penal dos vulneráveis" é convocado pelos seus defensores, como instrumento para afirmação e não violação de direitos; daí, porque, importanos sobremaneira, colher as contribuições da chamada teoria do reconhecimento.

Atualmente, a expressão "reconhecimento" está ligada à aceitação da existência de identidades e exprime a noção de consideração social a um dado segmento. Em seu bojo, estão inseridos o autorrespeito, a autoestima e a estima social dedicada a um certo grupo ou a uma certa identidade, porém é inaugurada enquanto filosofema, por Hegel, que em seus estudos em Jena, inicia a elaboração teórica acerca do reconhecimento intersubjetivo (HONNETH, 2003), ou seja, acerca de como nossa subjetividade, somente se torna plenamente desenvolvida, fundada na experiência com 0 outro.

Hegel afirma que a base do contrato social não seria uma luta pela autoconservação dos homens, mas, uma luta por reconhecimento. E explora a categoria do reconhecimento intersubjetivo, colocando-o como condição de pleno desenvolvimento das potencialidades humanas, analisando-o em três dimensões: o amor, o direito e a solidariedade. O conceito original de reconhecimento de Hegel foi expressado no vocábulo anerkennung ${ }^{3}$.

Tanto Axel Honneth como Charles Taylor desenvolvem suas formulações recuperando o conceito hegeliano de reconhecimento. Portanto, o colocam como requisito para a plena realização do indivíduo; enquanto para o primeiro o reconhecimento seria "a gramática moral dos conflitos sociais", o segundo identifica o reconhecimento, sobretudo, com autenticidade. Ambos são enquadrados entre o grupo dos teóricos que colocam as questões do reconhecimento no campo na ética.

3 Anerkennung, [reconhecimento], para HEGEL envolve não simplesmente a identificação intelectual de uma coisa ou pessoa (embora pressuponha caracteristicamente tal reconhecimento intelectual), mas a atribuição a essa coisa ou pessoa de um valor positivo, assim como a expressão explícita dessa atribuição. Assim ,quando Hegel se ocupa da luta pelo reconhecimento, ele está tratando problema de como nos tornamos uma pessoa plenamente desenvolvida pela obtenção de nosso status a partir da interação com os outros e não de um problema epistemológico relacionado a um processo de identificação que se dá na mente do “outro.”(INWOOD, 1997 
Para Charles Taylor, a intersubjetividade é formada a partir das sucessivas interações de cada indivíduo com o outro e com uma "comunidade de valores" de um determinado tempo e de uma determinada sociedade. Isto porque, no sentido hegeliano, reconhecimento significaria a aceitação das qualidades e demais características de um dado indivíduo, pelos demais; e este, sentindo-se assim, acolhido, se predisporia a reconhecer também o outro em sua especificidade, gerando dessa forma, "uma dinâmica de reconhecimento em espiral, onde a cada nova interação, e a cada nova experiência de reconhecimento, o individuo experimentaria e tomaria consciência de uma nova dimensão de sua subjetividade" (SOUZA, 2012 p. 135). Conflito e reconhecimento se condicionariam mutuamente, pois a lógica de reconhecimentos progressivos estimularia cada vez mais lutas e reivindicações por novos reconhecimentos.

Desse modo, para este autor, identidade é a compreensão de quem se é, ou a descoberta de sua diferença e autenticidade, que se dá em razão de interações dialógicas. A identidade é moldada pelo reconhecimento por parte dos outros. O processo de reconhecimento seria mediado por um preexistente ético, materializado em alguma forma de aceitação recíproca e intersubjetiva elementar que importaria em admitir, que o contrato social fosse uma realização refletida de direitos previamente reconhecidos e que os indivíduos se autodeterminassem tomando como referência a articulação reflexiva dos valores.

Nessa perspectiva, o homem se autointerpreta com base nas ideias guia e valores que ele colhe de sua época e de seu tempo. E isto se dá por meio da linguagem, posto que, é exatamente a linguagem que constitui o mundo de ideias em que o individuo está inserido. $\mathrm{O}$ lugar da linguagem na teoria de Taylor é crucial, pois é justamente a sua anterioridade ao indivíduo e à formação de sua identidade, que é a base da argumentação comunitarista, uma vez que, é a linguagem que permite aos homens compartilharem uma comunidade de sentidos.

O reconhecimento em Taylor traduz-se na luta pela sobrevivência da autenticidade, daquilo que é único. É, antes de tudo, a busca de cada indivíduo por sua identidade. Taylor se aproxima de Heidegger, ao nos apresentar um homem moderno que precisa conhecer-se, desvelar a sua verdade, que não é outra senão aquela que nasce da sua própria confrontação com a sua historicidade e sua faticidade. Para Taylor, a identidade é definida "a partir do horizonte em cujo âmbito posso tentar determinar, caso a caso o que é bom ou valioso (...) trata-se do horizonte dentro do qual sou capaz de tomar uma posição" (TAYLOR, 1997, p.4344). 
Honneth (2003) mantém de Hegel, a preocupação de levar em conta as três esferas sucessivas de interações e reconhecimento e colhe de Mead a abordagem intersubjetiva e aberta à verificação. Acerca da sua tipologia do reconhecimento, diz que "está inscrita na experiência do amor a possibilidade de autoconfiança, na experiência do reconhecimento jurídico, a do autorrespeito e , por fim, na experiência da solidariedade, a da autoestima ". (HONNETH, 2003, p.157).

O reconhecimento para Honneth passa pela autorrealização do indivíduo e se desenvolve de forma distinta em cada uma das três esferas. É fundada na experiência do reconhecimento que se pode entender plena, a subjetividade de cada indivíduo. Aquele que tem negado o reconhecimento não tem acesso aos requisitos mínimos para o pleno desenvolvimento humano, apresenta uma subjetividade prejudicada.

O reconhecimento pelo Direito é analisado por Honneth tendo como base dois questionamentos: Qual o tipo de autorrelação que caracteriza o reconhecimento pelo Direito? Como a pessoa desenvolve a consciência de ser sujeito de direitos? (HONNETH, 2003).

Para começar a responder tais questões, Honneth chama atenção para uma modificação que sofre este tipo de reconhecimento da transição da tradição para a modernidade Se na tradição se tinha o reconhecimento pelo Direito fundamentado em uma noção de status, na modernidade tem-se exatamente o contrário, não é mais permitido atribuir privilégios e exceções a quem quer que seja, em razão de status social. O Direito moderno tem de ser geral o suficiente para atender os interesses de todos os participantes da comunidade(HONNETH, 2003).

Com o surgimento de uma moral em uma sociedade pós-tradicional, ocorre a separação da função do direito e a função do juízo de valor. A questão passa a ser, no caso do direito, qual é a característica que define ou constitui um sujeito de direito? No caso do juízo de valor, como se pode desenvolver um sistema de valor capaz de medir as características de cada pessoa? Conclui-se que o primeiro aspecto está relacionado ao reconhecimento pelo Direito, o segundo já está ligado ao terceiro aspecto do reconhecimento social, a solidariedade. Na forma de reconhecimento pelo Direito, são levadas em consideração as características gerais do ser humano, já no reconhecimento pela valoração social, as singularidades vêm à tona.

Os sujeitos de direito se reconhecem mutuamente porque submetidos às mesmas leis de caráter geral e possuidores de autonomia individual, para decidir racionalmente entre as 
normas, tanto o caráter geral das leis, como a autonomia individual, encontram-se fundados na imputabilidade moral de todos os membros da comunidade.

Todos são sujeitos de direito em pé de igualdade, uma vez que todos protagonizaram um pacto racional imputável a todos, em que se decidiu a respeito de que categorias determinariam que alguém fosse um sujeito de direito. Os pressupostos sociais dessa participação racional são o que determina as propriedades a serem reconhecidas como universalmente humanas, e por isso, a luta pelo reconhecimento em verdade, é uma forma de pressão, a partir da qual, permanentemente, novas condições para a participação na formação pública da vontade emergem.

As capacidades juridicamente reconhecidas como atributos de um sujeito de direitos, podem ser alteradas de acordo com a situação social vigente, todavia, a direção seguida pela atribuição de direitos na modernidade é a da ampliação, por meio das lutas pelo reconhecimento das expectativas de direito, cabíveis, dentro do quadro de valores universalizado no acordo de vontades representado no contrato social.

Honneth, influenciado pelos escritos de T.H. Marshall, se esforça para demonstrar que as pressões por reconhecimento se dão justamente no processo em que o princípio da formação racional coletiva da vontade ganha validade social, com o reconhecimento jurídico, o que se dá progressivamente e ocorre por meio de uma luta pela ampliação do status igualitário, entre os membros de uma comunidade. Para Honneth, a própria evolução dos direitos fundamentais se dá em uma perspectiva de luta pelo reconhecimento.

Ainda sobre o reconhecimento pelo Direito, Honneth afirma que o ser reconhecido como sujeitos de direitos, implica, para o indivíduo, uma relação de autorrespeito, a qual viabiliza que este possa reconhecer-se possuidor de direitos, saiba ser merecedor do respeito de todos e, por isso mesmo, admita poder esperar que suas pretensões sejam aceitas e se transformem em direitos individuais (por essa razão isso somente pode se dar no ambiente pós-tradicional na presença de um critério de universalidade).

Já, a luta por reconhecimento, na esfera da solidariedade, seria a luta pelo respeito a uma determinada forma de vida. Ressalte-se a diferença: enquanto a luta pelo reconhecimento na esfera jurídica é a luta que procura legitimar a visão moral da igualdade (os requisitos para ser sujeito de direito que devem ser iguais para todos), e, dessa forma, ampliar o número de pessoas vistas pela sociedade como tais, a luta pelo reconhecimento na solidariedade visa à ampliação do número de formas de vida respeitadas pela sociedade. 
Na prática, o reconhecimento nesta terceira esfera da solidariedade, somente se dá por meio de uma articulação grupal, capaz de mostrar os valores de uma dada forma de vida como legítimos, o que instaura na sociedade uma luta permanente pela valorização simbólica das normas e valores de cada um dos grupos capazes de se organizar. Não se trata aqui, exclusivamente de grupos formalmente organizados, mas, sobretudo, de conflitos em que grupos de identidades tentam fazer valer suas formas de vida, a exemplo da luta dos homossexuais e das lutas feministas. Ressalte-se que o objetivo de tais lutas, mais que uma valorização simbólica, é a atenção pública a determinadas características da identidade do indivíduo, que são imprescindíveis para sua autorrealização e, no entanto, são desvalorizadas ou desrespeitadas no contexto social em que eles se encontram. Torna-se necessária assim, a luta para modificação dessa situação de desprestígio dessa dada forma de vida, a fim de que o indivíduo possa conquistar a autoestima, que é a valorização que o sujeito atribui a si mesmo por ser dotado da estima dos outros.

Impende ressaltar, que para Honneth, a experiência do desrespeito, propiciada pelo não reconhecimento, que pode engendrar, a depender da esfera de reconhecimento em que estejamos lidando, o sentimento de perda da autoconfiança, da autoestima e do autorrespeito, contém em si, a possibilidade de que a injustiça infligida ao sujeito se lhe revele em termos cognitivos e se torne motivo de resistência política (HONNETH, 2003), daí a ligação entre reconhecimento e conflito: o reconhecimento dá uma explicação moral ao conflito social.

Registro diferente faz Nancy Fraser (2007). Para esta autora, um indivíduo que padece de falta de reconhecimento é antes de tudo vítima de uma injustiça.

Nancy Fraser (2009) observa que na era pós-socialista, como ela chama o momento atual após a reconfiguração da ordem mundial, as lutas por redistribuição e contra a espoliação da classe trabalhadora, vão sendo substituídas por lutas por reconhecimento e, embora registre esse movimento de crescimento da atenção dada às diferenças culturais e às demandas por reconhecimento, deixa bem claro, que mesmo nos países centrais, as demandas por redistribuição não foram ainda superadas; pelo contrário, cresce a desigualdade social e os índices de desemprego, e, aumenta a parcela da população que não tem acesso às condições materiais mínimas para uma subsistência digna. Como é o caso dos Estados Unidos e da Europa continental, que enfrenta grave crise econômica em que as consequências já são sentidas pela população.

Para ela, reconhecimento e redistribuição são realidades distintas, mas indissociáveis, diferentemente de Honneth, que resumiu a natureza primária de todos os conflitos sociais à 
luta por reconhecimento, fazendo com que a lutas por redistribuição de renda estivessem subsumidas às questões do reconhecimento, a autora apresenta uma análise dualista dos conflitos sociais que permite elaborar um conceito de justiça social que agregue as duas dimensões: redistribuição e reconhecimento ( FRASER, 2003).

Enfatiza que a questão de fundo do reconhecimento não é a afirmação de uma identidade, mas é o "status social", não somente a consideração à estima social dedicada ao grupo, mas a sua capacidade de autodeterminação política e capacidade de participação. A consequência do não reconhecimento, para a autora, não é a depreciação da identidade do grupo ou a subjetividade prejudicada do individuo, porém, a subordinação política que lhe determina violação de direitos e lhe impede de participar como um par na sociedade. O que está em jogo não é somente a identidade (FRASER, 2007), é também ela. Propõe o critério da paridade participativa, para identificar as reivindicações de redistribuição e reconhecimento defensáveis, como somente aquelas necessárias a superação da situação de subordinação.

Registra que alguns segmentos apresentam-se deficientes, tanto quanto à redistribuição, quanto ao reconhecimento, seriam as "comunidades bivalentes" para quem seriam necessárias estratégias nas duas áreas. Fraser (2009) as distingue em ações afirmativas, que têm por objetivo, modificar os efeitos indesejados da não distribuição ou do não reconhecimento, sem, no entanto, atacar as suas origens, e as ações transformativas que objetivam a correção dos resultados, pela modificação das estruturas que os produzem.

\section{RECONHECIMENTO E DIREITO PENAL: RECRUDESCIMENTO E HIPERTROFIA DA FUNÇÃO SIMBÓLICA}

As reivindicações por criminalização de algumas condutas e o agravamento das já existentes, no que tange às condutas especificamente cometidas contra indivíduos pertencentes a grupos vulneráveis, inscrevem-se, sem dúvida, no quadro das mobilizações empreendidas nas lutas por reconhecimento travadas nas sociedades contemporâneas.

O não reconhecimento manifesta-se a partir de mecanismos de exclusão, seja ela material, seja cultural, ou mesmo as duas modalidades sobrepostas, como enfatiza Fraser (2007). O conflito penal tipificado na produção legislativa dos vulneráveis, encerraria assim, situações de não reconhecimento ou de reconhecimento errôneo, que podem descambar para lesão a bens jurídicos dos ofendidos. 
Lendo esse tipo de conflito pelas lentes fornecidas por Honneth (2003), é possível perceber que a criminalização de condutas perpetradas contra um determinado sujeito, por ostentar uma identidade ou pertencer a um grupo específico, tanto se insere na perspectiva do reconhecimento pelo Direito, onde o que está em jogo é o autorrespeito, como também, e muito mais enfaticamente, na esfera do reconhecimento pela solidariedade, cujo resultado consiste na autoestima.

No que concerne ao reconhecimento pelo Direito, viu-se que ele consiste justamente na definição daquelas propriedades que fazem de um ser humano uma pessoa, ou seja, os atributos que o tornam alguém capaz de estar em pé de igualdade em um procedimento de acordo racional, no dizer de Honneth, e que, se materializou em uma ampliação sucessiva de pretensões jurídicas individuais.

Dessa maneira, a assunção e a ampliação dos chamados direitos fundamentais, darse-iam exatamente no cenário da luta pelo reconhecimento na esfera do Direito. Observa-se que esse movimento pela crescente ampliação, não somente do conteúdo dos direitos básicos atribuídos a um ser humano, como também pela extensão de sua titularidade a grupos outrora excluídos, que caracteriza a dinâmica dos direitos fundamentais, vem acontecendo nos estados constitucionais contemporâneos, os quais trazem em suas estruturas normativas, um rol extenso de direitos fundamentais e os concedem em seu texto em uma perspectiva cada vez mais universalizante, quanto aos sujeitos.

Nesse sentido, para os grupos vulneráveis, cada um com seu percurso de reivindicações e com sua medida de sucesso nesta empreitada, a inclusão no catálogo de pessoas capazes de serem chamadas sujeitos de direito, ocorreu e vem ocorrendo progressivamente. Entretanto, em razão das dificuldades ostentadas por estes indivíduos, por conta de sua condição de vulnerabilidade, estas conquistas tendem a se limitar ao plano formal. São dotadas de baixa efetividade, o que em seus efeitos, equivale ao não reconhecimento, pois, o indivíduo sente-se desrespeitado, uma vez que as suas pretensões jurídicas as quais deveriam ser oponíveis a todos em razão de sua condição de pessoa, não surtem efeitos, nem sua voz é ouvida.

Da experiência de ver frustrada a pretensão de vivenciar a condição de sujeito de direitos, eloquentemente alardeada pelo Direito Constitucional, surge uma descrença no Direito enquanto instância capaz de garantir direitos e protegê-los de violações, o que na interpretação dos movimentos sociais, só pode ser superada pela ação vingadora do mais coercitivo dos direitos: o Direito Penal. As mobilizações são fundadas em um anseio genuíno 
por proteção e conduzem a um recrudescimento da resposta penal, destinada aos delitos cometidos contra indivíduos dos grupos vulneráveis, na medida em que os atores sociais entendem que a proteção às vítimas será tanto maior, quanto for a severidade da punição do tratamento penal, destinado aos seus ofensores: quanto mais punição, mais proteção.

Já no olhar do "Direito Penal dos vulneráveis", na perspectiva do reconhecimento pela solidariedade, o que sucede é que, se esta terceira esfera do reconhecimento, diz respeito à estima social atribuída a indivíduos ou grupos, em razão da maneira como são interpretadas as suas capacidades e especificidades ante o confronto com o quadro de valores da sociedade, operação que resulta em um saldo negativo no caso dos segmentos vulnerabilizados, os quais se mobilizam por um Direito Penal próprio, nada mais plausível, em sua ótica, que buscar inverter o vetor dessa valorização simbólica ${ }^{4}$.

Nesta empresa, é que os movimentos sociais buscam por meio dos instrumentos de controle do Direito Penal, na coerção pela ameaça da pena, ver seus valores e suas formas de vida valorizados. Assim, as mobilizações fundam-se em anseios de visibilidade e de valorização social frequentemente, e, considerações referentes à "efetividade" e "racionalidade" das legislações penais propostas são relegadas ao segundo plano, prevalecendo uma tendência clara para hipertrofia da função simbólica dessa produção penal.

Importa lembrar, que as exposições dos grupos vulneráveis a situações de desrespeito, violações de direitos e específicas formas de violência, está ligada à condição de "subordinação de status", aproveitando o argumento de Fraser, a que estão submetidos. Estes grupos enquadram-se na descrição que faz a autora das "coletividades bivalentes", grupos que sofrem tanto com a má distribuição econômica como com o não reconhecimento cultural e legal. Nessa perspectiva, a superação da injustiça a que estão submetidos, deveria se dar em duas frentes: de um lado, transformações de ordem político-econômica a eliminar a falta de acesso aos bens materiais necessários a uma vida digna que os aflige, e, de outro, a desconstrução dos padrões culturais institucionalizados, que os impedem de atuar de forma igual, paritária, no centro das decisões políticas. Pelas suas contradições e limitações, acredita-se não se prestar o Direito Penal, como instrumento de reconhecimento em nenhuma dessas abordagens.

4 HONNETH (2003) acredita que "quanto mais os movimentos sociais conseguem chamar a atenção da esfera pública para a importância negligenciada das propriedades e das capacidades representadas por eles de modo coletivo, tanto mais existe para eles a possibilidade de elevar na sociedade o valor social, ou mais precisamente a reputação de seus membros" (p.208) 


\section{CONCLUSÃO}

Não se deixa de reconhecer aqui que os segmentos vulnerabilizados são vítimas de formas específicas de violência, e que são merecedores de proteção estatal. O que se demonstra é que um Direito Penal específico não é a resposta à questão que pressupõe e antecede o conflito: o déficit de reconhecimento.

A escolha do Direito Penal pelos segmentos vulnerabilizados, como instrumento para consecução de uma finalidade, qual seja, a superação da vulnerabilidade e a conquista do reconhecimento, parece nascer, do histórico de violências e exclusões - que fazem parte do cotidiano e da história dos indivíduos, e grupos que apresentam como característica a vulnerabilidade social -, aparece implícito nessa escolha um raciocínio reativo, em que se espera que a violência e a coerção - próprias do Direito Penal- sejam capazes de neutralizar a violência e a subalternização impostas a esses atores sociais.

Aportamos, por fim, à ratificação da hipótese aqui testada de que o Direito Penal não é capaz, por suas limitações estruturais, por sua natureza e pelas características dos efeitos reais de sua operatividade, de promover reconhecimento.

Pelo contrário, ele pode ser um óbice ao reconhecimento, na medida em que reproduz uma cultura de retribuição, de afastamento e desconfiança entre os segmentos sociais, e na medida em que esgarça as relações comunitárias e de solidariedade. Em uma perspectiva macro, o uso do Direito Penal como estratégia para afirmação de direitos e para alcançar reconhecimento representa um sério prejuízo, porque este reforça a lógica de dominação que sustenta a situação de não reconhecimento e de vulnerabilidade e, principalmente, porque afasta os atores sociais do cerne da questão que passa por mudanças profundas da estrutura das sociedades contemporâneas, as quais devem se apresentar tanto como modificações de ordem redistributiva, como transformações de padrões culturais há muito arraigados, tudo isso por meio da participação e do protagonismo político.

Em perspectiva individual, não é demais lembrar que o Direito Penal reafirma a subalternização das vítimas quando lhes nega autonomia e lhes subtrai o conflito, ao mesmo tempo em que estigmatiza e anula o agressor. Os conflitos penais que dizem respeito ao "Direito Penal dos vulneráveis" têm como motivo uma situação de não reconhecimento - um indivíduo não enxergou o outro como este espera ser visto e merece ser enxergado. O Direito Penal não enseja esse (re)conhecimento entre os indivíduos, antes promove o afastamento pela culpa e pela dor. 
Portanto, o "Direito Penal dos vulneráveis" não só é incapaz de atender às expectativas nele depositadas, mas também mimetiza todos os defeitos deletérios do Direito Penal, o que - no horizonte da vulnerabilidade - se apresenta ainda mais pernicioso, uma vez que se está tratando com aqueles segmentos sociais que, no embate de forças pelo poder nas conflituais sociedades modernas, sempre suportaram o peso de ser "o outro", à custa de violência e anulação.

Considerando que os conflitos característicos do "Direito Penal dos Vulneráveis" dizem respeito a uma situação de não reconhecimento ou de reconhecimento errôneo por uma das partes, parece que, talvez, uma possibilidade de dotar de sentido e de racionalidade essa produção penal, aproximando-a das expectativas de geradora de reconhecimento que lhe atribuem as mobilizações sociais, seja a construção, para esses casos específicos, de um modelo se resolução de conflitos consensual o qual privilegie a autonomia, a responsabilidade e a implicação entre os indivíduos.

Proceder ao desnudamento crítico do "Direito Penal dos vulneráveis" e desqualificálo enquanto arma para a luta pelo reconhecimento, não significa desmerecer as legítimas reivindicações por igualdade e justiça encabeçadas pelos vulneráveis, nem muito menos negar a realidade de violências reais e simbólicas em que estão diuturnamente inseridos. Trata-se de um esforço e de um comprometimento com a transformação que somente poderá se dar com o realinhamento das expectativas depositadas no Direito Penal e com o deslocamento da energia política e do foco das reivindicações para conquistas que ostentem, verdadeiramente, o potencial emancipatório que falta ao Direito Penal.

\section{REFERÊNCIAS}

ABRAMOVAY, Míriam. Violência e Vulnerabilidade social na América Latina: desafios para as políticas públicas. Brasília: UNESCO, BID, 2002.

BARATTA, Alessandro. Criminologia crítica e crítica do Direito Penal: Introdução à Sociologia do Direito Penal. Rio de Janeiro: Revan, 2002

BECKER, Howard. Outsiders: estudos da sociologia do desvio. Tradução: Maria Luiza X. de A. Borges. Rio de Janeiro: Zahar, 2009

FRASER, Nancy. Da redistribuição ao reconhecimento? Dilemas da Justiça na era póssocialista. IN: SOUZA, Jessé (org.). Democracia hoje: novos desafios para a teoria democrática contemporânea. Brasília: Ed. UNB, 2001. p..245-282. 
FRASER, Nancy. Reconhecimento sem ética? Lua Nova - Revista de Cultura Política, São Paulo, no 70,p. 101-138, 2007. Disponível em \&lt;http://www.scielo.br/scielo.php? script=sci_arttext\&amp;pid=S010264452007000100006\&amp;lng=en\&amp;nrm=iso\&gt; . Acesso em 05 junho de 20

FRASER, Nancy. Reenquadrando a justiça em mundo globalizado. Lua Nova. São Paulo, n 77 ano 2009 p.11-39 Disponível em:<http://www.scielo.br/pdf/ln/n50/a08n50.pdf > .Acesso em: 09 de abril 2012.

FRASER, Nancy. Social Justice in the age of identity politcs: redistribution, recognition and participation. In: FRASER, Nancy; HONNET, Axel. Retribution or recognition? A political -philosophical Exchange. London/New York::Verso, 2003.

GIDDENS, Anthony. Modernidade e identidade.Tradução Plínio Dentzien. Rio de Janeiro: Zahar, 2002.

HÖFFE, Otfried. Justiça Política: fundamentação de uma filosofia crítica do direito e do Estado. Tradução de Ernildo Stein. São Paulo: Martins Fontes, 2001.

HONNET, Axel. Luta por reconhecimento: a gramática moral dos conflitos sociais. Tradução de Luiz Repa; Apresentação de Marcos Nobre. São Paulo: Ed. 34, 2003.

KIRCHHOFF, Gerad Ferdinand. Vitimologia: um empreendimento supérfluo? In: KOSOVSKI, Ester. PIEDADE JUNIOR, Heitor e MAYR, Eduardo. Vitimologia em debate. Rio de Janeiro: Forense, 1990.

KOSOVSKI, Ester. Fundamentos de Vitimologia In: KOSOVSKI, Ester; PIEDADE JUNIOR, Heitor e MAYR, Eduardo. Vitimologia em debate. Rio de Janeiro: Forense, 1990.

KOSOVSKI, Ester \& SÉGUIN, Élida. Temas de Vitimologia. Rio de Janeiro: Lumen Juris, 2002.

OLIVEIRA, Ana Sofia Schimitt. A vítima e o Direito Penal. São Paulo: Revista dos Tribunais, 1999.

PIEDADE JUNIOR, Heitor. Reflexões sobre Vitimologia e Direitos Humanos. In: KOSOVSKI, Ester \& SÉGUIN, Élida. Temas de Vitimologia. Rio de Janeiro, Lumen Juris, 2000 .

PIOVESAN, Flávia. Direitos Humanos desafios à ordem constitucional contemporânea. In: Cadernos de Direitos Constitucional, EMAGIS, p.21-23, 2006.

SCHEERER, Sebastian. L'entrepreneur moral atypique. Deviance et société, Géneve, 1985, vol 9. No 3, p.267-289.

SÉGUIN, Élida. Minorias e grupos vulneráveis: uma abordagem jurídica. Rio de Janeiro: Forense, 2002. 
SÉGUIN, Élida. Vitimologia no Terceiro Milênio. Rio de Janeiro: Forense, 2004.

SILVA-SANCHEZ, Jesús-Maria. A expansão do Direito Penal: aspectos da política criminal nas sociedades pós-industriais. São Paulo: Editora Revista dos Tribunais, 2002.

SOUZA, Jessé. Uma teoria Crítica do reconhecimento. Lua Nova. ${ }^{\circ} 50$. ano 2000. p.133241, Disponível em:< - http://www.scielo.br/pdf/ln/n50/a08n50.pdf > .Acesso em: 09 de abril 2012.

SWAANNINGEN, René Van Controle do crime no século XXI: analisando uma nova realidade. Revista Brasileira de Ciências Criminais Ano 11. São Paulo: Editora Revista dos Tribunais, v.42, p.103-119, janeiro-março de 2003.

SWAANNINGEN, René Van. TAYLOR, Ian. Ripensando la criminologia critica. Dei delitti e delle pene. 1993, n³, p.197-203.

TAYLOR, Charles. Multiculturalismo: Examinado a política de reconhecimento. Lisboa: Edições Piaget, 1998.

TAYLOR, Charles. As fontes do self: a construção da identidade moderna. São Paulo:Loyola, 1997.

TOSI, Giusseppe. História e atualidade dos direitos do homem. In:NEVES, Paulo Sérgio da Costa ( org.) Polícia e democracia: desafios à educação em Direitos Humanos. Recife: Gajop; Bagaço, 2002. p. 25 -48.

XIBERRAS, Martine. As teorias da exclusão: para uma construção do imaginário do desvio. Lisboa: Instituto Piaget, 1993. 